\title{
The options to minimize the surgical trauma to treat ocular diabetic complications and to improve postoperative recovery and quality of life require an individualized approach
}

\author{
Wolfgang F. Schrader • Tatjana Josifova
}

Received: 11 January 2010 /Accepted: 4 February 2010 /Published online: 16 March 2010

(C) European Association for Predictive, Preventive and Personalised Medicine 2010

\begin{abstract}
Within the past ten years, small incision parsplana vitrectomy, and refined microsurgical techniques, together with the introduction of various intravitreally applied drugs, significantly improved the anatomical and functional outcome. Unfortunately many diabetic patients with vitreoretinal complications also have cataract. In diabetic retinopathy, the benefit of simultaneous cataract surgery was long under debate due to possible side effects such as fibrinous reaction or secondary glaucoma. We review recent reports about the results of PPV for complication of diabetic retinopathy and the influence of a simultaneous cataract surgery, that compare different surgical approaches. Pars plana vitrectomy carried out with conventional $0,9 \mathrm{~mm}$ incisions (20G PPV) were related to higher incidences of postoperative inflammatory reactions and to a higher frequency of postoperative hypertensive events as compared to small incision vitrectomy (23G $\mathrm{PPV})$. Postoperative recovery was faster in eyes with $23 \mathrm{G}$ surgery than after $20 \mathrm{G}$ surgery, with no delay by a simultaneous cataract surgery. A 23G-PPV improves the postoperative recovery and the quality of life for the diabetic patient. Cataract is no longer an obstacle for a vitreoretinal surgery. Postoperative recovery is faster and the new technique has less side effects than the conven-
\end{abstract}

\section{W. F. Schrader $(\bowtie)$}

Maximilians Augenklinik,

Erlenstegenstr. 30,

90491 Nürnberg, Germany

e-mail: mail@drwschrader.de

T. Josifova

Universitäts-Augenklinik Basel,

Mittlere Strasse 91,

4031 Basel, Switzerland tional technique. In the future, a drug assisted vitrectomy will further reduce the surgical trauma. However, the new options are not equally benefitial for all patients. A further improvement in the quality of life will require a more individualized approach of microsurgical treatment for ocular complications of diabetes.

Keywords Small incision ocular microsurgery.

Drug assisted vitrectomy . Postoperative inflammation .

Ocular hypertension - Diabetic retinopathy - Quality of life .

Prophylaxis

\section{Introduction}

Diabetes care and eye diseases: status quo

Diabetes mellitus is an increasing problem in healthcare with a high socioeconomic impact. Around 8 million diabetics live in Germany, not all of whom are aware of their disease [1]. Around 1.5 million are visually impaired due to diabetic retinopathy. Diabetic retinopathy is the leading cause for blindness in the age below 65 in the industrialized world.

Ocular manifestations of diabetes mellitus are exudative or proliferative vitreoretinopathy [2], vitreous hemorrhage, tractional retinal detachments, cataract and secondary glaucoma.

New developments in instrumentation allow very subtle vitreoretinal microsurgery, followed by a minimal postoperative inflammatory reaction, but require excellent conditions for illumination and observation. Therefore, not rarely the surgeon has to decide whether to combine a vitreoretinal surgery with a cataract surgery [3]. 
The problem of coexisting cataract and retinal disease in diabetic patients

A cataract may already preoperatively appear in such an advanced stage, that a pars plana vitrectomy is not possible, before cataract surgery has been performed. However, also a less advanced cataract may initially allow a pars plana vitrectomy. But due to osmotic alterations during surgery it may advance within minutes during the vitrectomy procedure and impair the visibility of the retinal structures, so that the subtle surgery cannot be completed without simultaneous cataract surgery. Already a limited pars plana vitrectomy with macular surgery is regularly followed by a significant cataract within months [4], so that the issue of a prophylactic cataract surgery has to be addressed.

If a significant cataract is already present at the time, the pars plana vitectomy is indicated, it has to be decided, whether to perform a cataract surgery prior to the vitrectomy or simultaneously. In some institutions, cataract surgeries and vitrectomies are performed by different surgeons, while in other institutions both procedures are performed by the same surgeon. This paper will not discuss the logistic issue of a complex surgery performed by two surgeons, but will focus on the results that can be achieved by modern surgery.

However, the aforementioned ocular manifestations of diabetes (such as exudative or proliferative vitreoretinopathy [2], vitreous hemorrhage, tractional retinal detachments, cataract and secondary glaucoma) have in common an impaired blood retinal barrier. Any intraocular surgical procedure additionally affects this barrier. As a consequence, surgery for a complication of diabetic retinopathy is followed by an increased postoperative inflammatory reaction as compared to other indications.

\section{Combination of pars plana with simultaneous cataract surgery versus a two separate procedures}

After cataract surgery in a diabetic patient, the potential visual recovery may be limited by a postoperative fibrinous membrane or by an early after-cataract formation [5]. This complication was even more frequently observed following cataract surgery with an implantation of a Polymethylmethacrylate (PMMA) intraocular lens as compared to a modern acryl lens. Therefore, 25 years ago, a simultaneous cataract surgery was avoided if possible, and an implantation of an intraocular lens in an eye with active proliferative retinopathy was regarded as contraindicated. In younger patients, moderate lens opacities have been found to progress following vitrectomy only in 5\% of the cases [6]. However, most of the diabetic patients scheduled for vitrectomy nowadays are older and will develop cataract in a significantly higher percentage.
25 years ago, vitreoretinal surgery in an eye with an advanced proliferative diabetic retinopathy including iris neovascularization and advanced cataract as well as the necessity to perform a lensectomy during vitrectomy was associated with an unfavorable outcome and thus should be avoided [7]. Not rarely, a cataract surgery with intraocular lens implantation was followed by a deterioration of the diabetic retinopathy during the postoperative healing process resulting in a neovascular glaucoma before vitrectomy could be performed. Following extracapsular cataract extraction with intraocular lens (IOL) implantation, a rubeosis iridis and neovascularization within the lens capsule supporting the IOL developped, a condition termed rubeosis capsularis [8]. On the other hand a vitrectomy with preservation of the lens in an eye with advanced diabetic retinopathy and rubeosis iridis was followed by a fibrinoid reaction, continued inflammation and resulted in phthisis in $13 \%$, because the peripheral retina could not be adequately treated and peripheral vitreoretinal membranes could only insufficiently be dissected [9]. The occurrence of silicone oil-induced cataract following vitreoretinal silicone oil surgery is an unavoidable complication due the metabolic changes. Following extracapsular cataract extraction, extreme fibrosis und shrinkage of the posterior lens capsule was observed.

To overcome the dilemma of progressing proliferations and massive fibrinous reactions following cataract surgery in an eye that also urgently needed vitreoretinal surgery, it was advised to perform an intracapsular cataract extraction without an IOL during vitreoretinal surgery and IOL-implantation at the earliest 3 months after all retinal interventions have been completed and the retina is stable [10].

After the introduction of small incision surgeries and ameliorated lens materials the frequency of the aforementioned complications could be reduced. In addition, a shorter surgical time helped to reduce the postoperative inflammatory effect. In addition, nowadays most of the diabetic patients receive panretinal photocoagulation prior to vitreoretinal surgery so that the proliferations are less fulminant even in advanced situations than they were 25 years ago. 10 years ago it was found that cataract extraction and simultaneous IOL implantation during vitreous surgery for proliferative diabetic retinopathy may improve the visual outcome in more than $90 \%$ of selected eyes without significant complications [11].

On the other hand a cataract surgery in previously vitrectomized eyes is still difficult and associated with a higher complication rate. In a prospective study of 100 consecutive eyes of patients who developed a cataract after PPV, intraoperative complications including posterior capsular tears (4\%), luxated nucleus into vitreous $(2 \%)$, and zonular dialysis $(5 \%)$ and postoperative complications including vitreous hemorrhage $(6 \%)$, retinal redetachment 
(4\%), pupillary synechiae (6\%), ocular hypertension (4\%), and fistulation $(3 \%)$ were found more frequently than in nonvitrectomized eyes. The visual results were limited by retinal comorbidity as well as by the surgical complications [12].

Nowadays, it is widely believed, that a cataract surgery performed together with a vitreoretinal surgery, does not increase the time needed for the vitreoretinal part of the surgery and does not increase the complication rate [13]. We could confirm these findings $[14,15]$. Furthermore, the combination of both procedures eliminates the need for further surgery, ameliorates the visibility within the vitreoretinal procedure and enhances the postoperative visual recovery [16]. The time needed for hospitalization is shorter after a combined surgery as compared to separate surgeries $[14,15]$. Even more, the postoperative development of iris and angle neovascularization could be completely prevented by combining vitrectomy with phacoemulsification, while it was $15 \%$ in the vitrectomy alone group [17].

When pars plana vitrectomy is combined with cataract surgery, the extent of the postoperative inflammatory reaction and the postoperative complications may depend on the following factors:

1. surgical approach of cataract surgery

2. composition of the intraocular lens material

3. surgical approach to vitrectomy

4. duration of surgery

We will further discuss to what extent these factors may determine the postoperative inflammatory reaction and how further complications of diabetes in the eye may be prevented.

\section{Surgical approach of cataract surgery}

As already mentioned above, the results of a combined extracapsular cataract surgery (ECCE), that required an $11 \mathrm{~mm}$ corneoscleral incision, a posterior chamber intraocular lens implantation (PC/IOL) and a $20 \mathrm{G}$ pars plana vitrectomy were limited by a fibrinous reaction and a potentially progressing neovascularization in patients with advanced diabetic retinopathy. In less advanced stages of retinopathy, the combined ECCE/PC-IOL implantation and pars plana vitrectomy was a well-tolerated surgical procedure for diabetics, which can provide clear anterior and posterior segment media already 20 years ago, with a doubling of visual acuity in the average [18].

When vitrectomy was combined with cataract removal by phacoemulsification instead of extracapsular extraction, the complication rate was further reduced. Suzuki et al. reviewed postoperative complications after simultaneous vitrectomy, phacoemulsification, aspiration, and acryl lens insertion. Combined surgery was performed in 155 eyes with diabetic retinopathy between 1995 and 1997. Postoperative observation was continued in all of them for more than 6 months. In patients with diabetic retinopathy, reoperations were needed for intravitreal hemorrhage in 21 eyes $(13.5 \%)$, rubeotic glaucoma in 6 eyes $(3.9 \%)$, other diseases in 4 eyes $(2.6 \%)$, and a removal of an intraocular lens was needed in 10 eyes (6.5\%). [19]. Yet, a fibrinous exudation was found in $30 \%$ of the eyes [20].

After having changed from phacoemulsification via a sclerocorneal tunnel incision to a clear cornea incision we could show that the rate of a fibrinous exsudation was reduced from $38 \%$ to $26 \%$ [21]. Thus we could confirm Diolaiuti et al, who found a rate of a limited postoperative fibrin formation in $22 \%$ of eyes [22].

A bimanual technique for phacoemulsification may allow an even better stabilization of the anterior chamber during vitreoretinal surgery without serious postoperative complications. This technique improves the quality of combined surgery, ensures stability of the anterior chamber, reduces postoperative astigmatism and lowers the risk of inflammation [23].

\section{Composition of the intraocular lens material}

Implantation of a PMMA-IOL more often causes a postoperative fibrinous reaction than a foldable acrylic IOL $[21,23]$. The inflammatory reaction of a foldable acrylic IOL is comparable to that of a heparin coated PMMA IOL. Foldable acrylic IOLs allow small incisions ranging between 3.2 and $1.8 \mathrm{~mm}$ with a minimized postoperative astigmatism, and a minimized risk of inflammation [23].

\section{Surgical approach to vitrectomy}

While 23-gauge pars plana vitrectomy demonstrated shortterm visual outcomes and complication rates comparable to those reported with 20- and 25-gauge systems [24], we could show a reduced postoperative inflammatory reaction following 23G PPV as compared to 20G PPV, not only for PPV alone, but also for procedures combined with cataract surgery with a clear cornea approach [25]. In the postoperative antiinflammatory treatment we used dexamethasone eye drops either 6 times or 12 times a day. If the reaction was very pronounced, we injected $4 \mathrm{mg}$ of dexamethasone subconjunctivally. For the analysis, this would equal 24 drops (24 DE or drop equivalents) of dexamethasone. Other drugs, that modulate the postoperative inflammatory reaction, were not used. The approach to PPV affected the postoperative inflammatory reaction as well as the approach 
to cataract surgery: a $20 \mathrm{G}$ PPV combined with a $6 \mathrm{~mm}$ wide sclerocorneal tunnel caused a higher degree of ocular injury and therefore a higher postoperative inflammatory response with a fibrine reaction in $38 \%$ of cases and a steroid use of 17.2 drop equivalents (DE). The injury caused by a $20 \mathrm{G}$ PPV combined with a $3 \mathrm{~mm}$ clear cornea tunnel incision is smaller, resulting in less frequent fibrine reactions $(26 \%)$ and a reduced steroid consumption (12.4 DE). The $23 \mathrm{G}$ PPV approach combined with a $3 \mathrm{~mm}$ clear cornea tunnel for cataract surgery produces the least trauma, with rare fibrine reactions (3\%) and only 8.6 DE of local steroids. Thus we were able to confirm findings by Valmaggia [26], who also found a reduced inflammatory reaction not only following $25 \mathrm{G}$ PPV as compared to $20 \mathrm{G}$ PPV alone, but also following with cataract surgery combined procedures. However, the time needed for the final visual recovery does not differ between small and standard incision vitrectomy ( $25 \mathrm{G}$ as compared to $20 \mathrm{G}$ ) [27].

\section{Future developments: drug assisted vitrectomy}

The use of triamcinolone acetonide stains the vitreous and reduces a postoperative inflammatory reaction. Birinci demonstrated that a combined clear corneal phacoemulsification with foldable intraocular lens implantation (IOL) and triamcinolone assisted pars plana vitrectomy in patients with proliferative diabetic retinopathy simplified the surgery and decreased the postoperative inflammation [28]. As compared to our results, the rate of a fibrinous iritis was further reduced from $26 \%$ to $11 \%[21,28]$. However, the use of intravitreal triamcinolone is associated with a $30 \%$ risk of a postoperative ocular hypertension or secondary glaucoma [29], However, intravitreal triamcinolone should not be applied subsequent to vitrectomy and peeling of the membrana limitans interna [30], as it could be shown that triamcinolone crystals demonstrate pronounced cytotoxicity if allowed to directly adhering to denuded ganglion cells [31].

Mechanical vitrectomy is incomplete. Remnants of the cortical vitreous may cause vitreoretinal traction and (re) proliferation of cells. A pharmacologic vitreolysis with microplasmin facilitates a complete posterior vitreous detachment without mechanical manipulation at the vitreoretinal interface and is a less traumatic approach than vitrectomy $[32,33]$. It might be of a special benefit in retinal diseases characterized by fibrocellular and fibrovascular proliferations, such as diabetic macular edema and proliferative retinopathy, in order to prevent advanced stages of disease [33]. In a completely vitrecomized eye the oxygen supply to the retina is improved, resulting in a lower expression of vasoactive substances such as vascular endothelial growth factor [33, 34].
An intravitreal injection of bevacizumab significantly decreased the free VEGF in the aqueous humor by 7 days, an intraoperative hemorrhage was less likely to occur [35]. An intravitreal injection of bevacizumab injection before vitrectomy for PDR facilitates the surgery, reduces the time needed for surgery by $30 \%$, and may improve the visual acuity results of the operation [36]. It was shown in a randomized study that it also decreases the rate of postoperative vitreous hemorrhage [37].

\section{Duration of surgery}

Over the last 25 years the time needed for PPV was largely reduced from about $90 \mathrm{~min}$ to $30 \mathrm{~min}$. However, the reduced inflammation is not primarily related to a reduced surgical time. We previously investigated the cut-closuretime for $20 \mathrm{G}$ and $23 \mathrm{G}$ PPV and found out that is did not differ significantly $(18,5 \pm 5,9 \mathrm{~min}$ vs $19,8 \pm 6,4 \mathrm{~min}$ for $20 \mathrm{G}$ vs $23 \mathrm{G}-\mathrm{PPV}$ ), while the inflammatory reaction was further reduced following 23G PPV as compared to 20G PPV [25]. The reduction of time needed for the preparation and closure of the sclerotomies in $23 \mathrm{G}$ and $25 \mathrm{G}$ vitrectomies is compensated by the longer time needed for the vitrectomy itself with the smaller instruments [27, 38]. Therefore, we conclude from our data, that the observed effect of a reduced inflammatory reaction following $23 \mathrm{G}$ PPV as compared to $20 \mathrm{G}$ PPV is induced by minimizing the surgical trauma itself.

\section{Combination of vitrectomy with cataract suregry versus two sequential surgeries improves individual outcomes}

Combining vitrectomy with phacoemulsification and posterior capsulectomy allows patients who often have bilateral vitreoretinal disease to come to a stable postoperative vision in the eye requiring vitreous surgery much earlier than three separate procedures spread out over months or years [39]. Combined surgery may prevent a second operation for postvitrectomy cataract, allowing earlier visual rehabilitation [40].

\section{Minimizing the surgical trauma will further improve the individual outcome}

Minimizing the surgical trauma for the cataract part of the surgery as well as for the vitrectomy part results in a reduced postoperative inflammatory reaction [25]. In addition a reduced surgical time further reduces the postoperative inflammatory reaction. However the recent change from standard 20G PPV to 23G PPV did not reduce the overall needed time between cut and suture [25]. The 
reduction of time needed for the preparation and closure of the sclerotomies in $23 \mathrm{G}$ and $25 \mathrm{G}$ vitrectomies is compensated by the longer time needed for the vitrectomy itself with the smaller instruments [27, 38]. The use of triamcinolone acetonide may even further simplify surgery and decrease the postoperative inflammation [28].

We have shown that a combination of small incision vitrectomy with a small incision cataract surgery via a clear cornea approach did not increase the postoperative inflammatory reaction and the amount of antiinflammatory drugs needed postoperatively when compared to vitrectom alone [21]. In a combined procedure, neither the time needed for vitreoretinal surgery is prolonged nor the complication rate increased [13]. Rather, the intraoperative visualization of the vitreoretinal structures is ameliorated and the postoperative visual recovery is quicker [16]. Finally, the economic burden of a combined procedure is lower than for two separate procedures [41].

\section{Predictive indicators that determine the best individualized treatment}

A high degree of neovascularization, especially in the anterior part of the eye, was a prognostic indicator for an unfavorable outcome. With the recent advent of intravitreally applied drugs that block the neovascular effect of the vasoproliferative growth factor (VEGF), this problem can be overcome now. A patient with a coexisting cataract, proliferative retinal disease and iris neovascularization or even with a neovascular glaucome should be pretreated with an intravitreally applied anti-VEGF substance, such as bevacizumab or ranibizumab about 3-7 days prior to the combined surgery [36, 37]. An intravitreal injection of bevacizumab significantly decreased the free VEGF in the aqueous humor by 7 days, an intraoperative hemorrhage was less likely to occur [35]. An intravitreal injection of bevacizumab injection before vitrectomy for PDR facilitates the surgery, reduces the time needed for surgery by $30 \%$, and may improve the visual acuity results of the operation [36]. It was shown in a randomized study that it also decreases the rate of postoperative vitreous hemorrhage [37].

\section{Conclusion}

The developments in modern small incision techniques in ocular microsurgery helped to reduce the postoperative inflammatory reaction and thus improved the postoperative recovery and the quality of life for the diabetic patient. Due to the reduced surgical trauma, the diabetic patient may now receive a complete treatment without risking the side effects of this treatment. An impending cataract is no longer an obstacle for a vitreoretinal surgery as both problems can be addressed simultaneously without risking an impaired functional outcome. Postoperative recovery is faster and the new technique has less side effects than the conventional technique. Thus, following minimally-invasive diagnostics, the new micro-incisional techniques allow an optimal therapy planning and a personalized patient treatment, combined with a substantial improvement of the quality of life when compared to previous techniques. The addition of drugs, such as steroids or anti-VEGF drugs or microplasmin, may facilitate and fasten the surgery and further minimize the surgical trauma. In addition, the new surgical techniques allow a more complete surgery, and the combination of techniques that previously had to be separated into distinct surgical procedures, result in a reduction of the economic burden of diabetes complications in the eye. However, the classic therapeutic options like laser coagulation still have their place in the portfolio of treatment strategies. The enlarged portfolio of treatment options requires an individualized approach, as not all options are equally benefitial for all diabetic patients. Thus, a further evaluation in prospective studies is necessary to reach the goal of an evidence based, predictive and personalized medicine.

Financial Disclosure None reported.

\section{References}

1. Deutsche Diabetes Union (ed.) Deutscher Gesundheitsbericht Diabetes 2007. In, Mainz; 2006.

2. Hesse L, Heller G, Kraushaar N, et al. Klinische Bedeutung einer Stadieneinteilung der proliferativen diabetischen Vitreoretinopathie. [The predictive value of a classification for proliferative diabetic vitreoretinopathy]. Klin Monatsbl Augenheilkd. 2002;219:46-9.

3. Scharwey K, Pavlovic S, Jacobi KW. Combined clear corneal phacoemulsification, vitreoretinal surgery, and intraocular lens implantation. J Cataract Refract Surg. 1999;25:693-8.

4. Livingstone BI, Bourke RD. Retrospective study of macular holes treated with pars plana vitrectomy. Aust N Z J Ophthalmol. 1999;27:331-41.

5. Scharwey K, Pavlovic S, Jacobi KW. Fruhe Hinterkapselfibrose nach kombinierter Katarakt- und vitreoretinaler Chirurgie mit intraokularer Luft/SF6-Gastamponade. Klin Monatsbl Augenheilkd. 1998;212:149-53.

6. Gnad HD. Die Vitrektomie via pars plana. Eine histologische Studie und Analyse klinischer Ergebnisse.[Vitrectomy via pars plana. A histological study and an analysis of clinical results (author's transl)]. Wien Klin Wochenschr Suppl. 1980;108:1-22.

7. Thompson JT, De Bustros S, Michels RG, et al. Results and prognostic factors in vitrectomy for diabetic traction retinal detachment of the macula. Arch Ophthalmol. 1987;105:497-502.

8. Eifrig DE, Hermsen V, Mcmanus P, et al. Rubeosis capsulare. J Cataract Refract Surg. 1990;16:633-6.

9. Oldendoerp J, Spitznas M. Der Einfluss von Rubeosis iridis und aktiven Neovaskularisationen am Fundus auf die Ergebnisse der 
Glaskorperchirurgie bei der proliferativen diabetischen Retinopathie. [Effect of rubeosis iridis and active neovascularization of the fundus on vitreous surgery in diabetic retinopathy]. Klin Monbl Augenheilkd. 1988;192:650-9.

10. Biermeyer H, Kroll P. Vorschlag zur Linsenimplantation nach vitreoretinaler Silikonoelchirurgie. [Recommendation for lens implantation following vitreoretinal silicone oil surgery]. Klin Monbl Augenheilkd. 1990;197:6-8.

11. Hui Y, Wang L, Huang W, et al. Simultaneous intraocular lens implantation during vitreous surgery for treatment of proliferative diabetic retinopathy. Zhonghua Yan Ke Za Zhi. 2002;38:598-602.

12. Pardo-Munoz A, Muriel-Herrero A, Abraira V, et al. Phacoemulsification in previously vitrectomized patients: an analysis of the surgical results in 100 eyes as well as the factors contributing to the cataract formation. Eur J Ophthalmol. 2006;16:52-9.

13. Jun Z, Pavlovic S, Jacobi KW. Results of combined vitreoretinal surgery and phacoemulsification with intraocular lens implantation. Clin Exp Ophthalmol. 2001;29:307-11.

14. Schrader WF, Unger S. Kataraktoperation kombiniert mit Parsplana Vitrektomie bei diabetischer Retinopathie im Vergleich zu anderen Indikationen. Klin Monatsbl Augenheilkd. 2002;220:S31.

15. Unger S. Beeinflussung der postoperativen Entzündungsreaktion nach kombinierter PPV mit Kataraktoperation und Hinterkammerlinsenimplantation bei Diabetikern und Nichtdiabetikern In: Dept. of Ophthalmology. University of Würzburg, Würzburg; 2005.

16. Leyland MD, Schulenburg WE. Combined phacoemulsificationvitrectomy surgery: technique, indications and outcomes. Eye. 1999;13:348-52.

17. Tseng HY, Wu WC, Hsu SY. Comparison of vitrectomy alone and combined vitrectomy, phacoemulsification and intraocular lens implantation for proliferative diabetic retinopathy. Kaohsiung $\mathbf{J}$ Med Sci. 2007;23:339-43.

18. Foster RE, Lowder CY, Meisler DM, et al. Combined extracapsular cataract extraction, posterior chamber intraocular lens implantation, and pars plana vitrectomy. Ophthalmic-Surg. 1993;24:446-52.

19. Suzuki Y, Sakuraba T, Mizutani H, et al. Postoperative complications after simultaneous vitrectomy and cataract surgery. Ophthalmic Surg Lasers. 2001;32:391-6.

20. Rivas-Aguino P, Garcia-Amaris RA, Berrocal MH, et al. Vitrectomia pars plana, facoemulsificacion e implante de lente intraocular para el manejo de catarata y retinopatia diabetica proliferativa: comparacion de tecnica quirurgica combinada versus en dos tiempos. [Pars plana vitrectomy, phacoemulsification and intraocular lens implantation for the management of cataract and proliferative diabetic retinopathy: comparison of a combined versus two-step surgical approach]. Arch Soc Esp Oftalmol. 2009;84:31-8.

21. Schrader WF, Schunder S. Postoperative recovery following $23 \mathrm{G}$ vitrectomy is not delayed by a simultaneous clear cornea phacoemulsification. In: 107. DOG-Kongress. Leipzig; 2009.

22. Diolaiuti S, Senn P, Schmid MK, et al. Combined pars plana vitrectomy and phacoemulsification with intraocular lens implantation in severe proliferative diabetic retinopathy. Ophthalmic Surg Lasers Imaging. 2006;37:468-74.

23. Nawrocki J, Michalewska Z, Michalewski J, et al. Cool phaco in combined phacoemulsification and vitrectomy surgery. Klin Oczna. 2006;108:16-9.

24. Lott MN, Manning MH, Singh J, et al. 23-gauge vitrectomy in 100 eyes: short-term visual outcomes and complications. Retina. 2008;28:1193-200.
25. Schrader WF, Schunder S, Unger S. Hat die 23G-Vitrektomie kombiniert mit Phakoemulsifikation der Linse in Clear Cornea Technik Vorteile gegenüber der klassischen Vitrektomie. In: Tetz MR, Auffahrt GU, Pham DT, editors. 22. Kongress der Deutschsprachigen Gesellschaft für Intraokularlinsen-Implantation, Interventionelle und Refraktive Chirurgie. Köln: Biermann Verlag; 2009. p. 267-75.

26. Valmaggia C. Pars plana vitrectomy with 25 -gauge instruments in the treatment of idiopathic epiretinal membranes. Klin Monatsbl Augenheilkd. 2007;224:292-6.

27. Chang CJ, Chang YH, Chiang SY, et al. Comparison of clear corneal phacoemulsification combined with 25 -gauge transconjunctival sutureless vitrectomy and standard 20-gauge vitrectomy for patients with cataract and vitreoretinal diseases. J Cataract Refract Surg. 2005;31:1198-207.

28. Birinci H. Surgical results of triamcinolone assisted pars plana vitrectomy combined with phacoemulsification in diabetic patients. Open Ophthalmol J. 2008;2:5-8.

29. Vasconcelos-Santos DV, Nehemy PG, Schachat AP, et al. Secondary ocular hypertension after intravitreal injection of $4 \mathrm{mg}$ of triamcinolone acetonide: incidence and risk factors. Retina. 2008;28:573-80.

30. Jaissle GB, Bartz-Schmidt KU, Szurman P. Optikusatrophie nach epiretinalen Triamcinolon-Ablagerungen in einem Auge mit entfernter Membrana limitans interna. [Optic atrophy subsequent to epiretinal triamcinolone deposits in an eye following inner limiting membrane peeling]. Ophthalmologe. 2008;105:575-77.

31. Szurman P, Sierra A, Kaczmarek R, et al. Different biocompatibility of crystalline triamcinolone deposits on retinal cells in vitro and in vivo. Exp Eye Res. 2007;85:44-53.

32. Lopez-Lopez F, Rodriguez-Blanco M, Gomez-Ulla F, et al. Enzymatic vitreolysis. Curr Diabetes Rev. 2009;5:57-62.

33. Gandorfer A. Objective of pharmacologic vitreolysis. Dev Ophthalmol. 2009;44:1-6.

34. Stefansson E. Physiology of vitreous surgery. Graefes Arch Clin Exp Ophthalmol. 2009;247:147-63.

35. Matsuyama K, Ogata N, Jo N, et al. Levels of vascular endothelial growth factor and pigment epithelium-derived factor in eyes before and after intravitreal injection of bevacizumab. Jpn J Ophthalmol. 2009;53:243-8.

36. Modarres $\mathrm{M}$, Nazari $\mathrm{H}$, Falavarjani $\mathrm{KG}$, et al. Intravitreal injection of bevacizumab before vitrectomy for proliferative diabetic retinopathy. Eur J Ophthalmol. 2009;19:848-52.

37. Ahmadieh H, Shoeibi N, Entezari M, et al. Intravitreal bevacizumab for prevention of early postvitrectomy hemorrhage in diabetic patients: a randomized clinical trial. Ophthalmology. 2009;116:1943-8.

38. Kellner L, Wimpissinger B, Stolba U, et al. 25-gauge vs 20-gauge system for pars plana vitrectomy: a prospective randomised clinical trial. Br J Ophthalmol. 2007;91:945-8.

39. Lahey JM, Francis RR, Kearney JJ, et al. Combining phacoemulsification and vitrectomy in patients with proliferative diabetic retinopathy. Curr Opin Ophthalmol. 2004;15:192-6.

40. Lahey JM, Francis RR, Kearney JJ. Combining phacoemulsification with pars plana vitrectomy in patients with proliferative diabetic retinopathy: a series of 223 cases. Ophthalmology. 2003;110:1335-9.

41. Ando A, Nishimura T, Uyama M. Surgical outcome on combined procedures of lens extraction, intraocular lens implantation, and vitrectomy during removal of the epiretinal membrane. Ophthalmic Surg Lasers. 1998;29:974-9. 